ROCZNIKI HUMANISTYCZNE

Tom LXVIII, zeszyt 2 - 2020

DOI: http://dx.doi.org/10.18290/rh20682-8

JOSÉ LUIS ORELLA

\title{
EL COOPERATIVISMO AGRARIO - PRIMERA ACCIÓN DEL CATOLICISMO SOCIAL EN ESPAÑA
}

En el siglo XX, la sociedad europea se enfrentó al reto de una modernidad que transformaba el mundo material y socialmente. Por un lado, un capitalismo emergente, dentro de un liberalismo político, que defendía un individualismo radical e independiente de toda visión trascendente del mundo. Por otro lado, un socialismo transformador que desembocaba en la búsqueda de una sociedad ideal ordenada por un Estado omnipresente, pero donde el hombre formaba una partícula lo suficientemente pequeña para no poder alterar el ritmo de la sociedad perfecta, si se equivocaba. La revolución rusa de 1917 sustituyó a la francesa como icono de los revolucionarios, y un nuevo modelo social sin Dios se hacía presente.

Ante esta dualidad, los católicos resultaron ser los pioneros de una tercera vía que sostenía la independencia de la persona, pero integrada en una sociedad donde cada persona tenía una misión que cumplir y resultaba complementaria de la de su vecino, pero era necesaria la conjunción de todas para que tuviesen un sentido armonioso. Este modo, orgánico de ver la vida se debía encauzar en la elaboración de un camino de defensa de la dignidad de la persona. El catolicismo social fue un intento de humanizar una sociedad que aceleraba una secularización causada por el liberalismo. Pero también, una respuesta a un sistema que veía surgir un socialismo materialista con vocación de controlar de manera totalitaria todos los resortes de la vida humana. La Encíclica Rerum Novarum de León XIII, del 15 de mayo de 1891, y la Quadragessimo Anno de Pío XI, del 15 de mayo de 1931, ayudaron a preconizar una tercera vía entre el capitalismo y el socialismo, por parte de los católicos. Las excelencias de un humanismo, que, en definitiva, no dejaba de

Prof. JosÉ LuIS ORELla - Profesor titular de Historia Contemporánea en la Universidad CEU San Pablo (España); dirección de correspondencia — correo electrónico: jlorella@ceu.es; ORCID: https://orcid.org/0000-0003-2727-5955. 
decir lo que la Doctrina Social de la Iglesia llevaba diciendo desde los primeros tiempos de las comunidades cristianas.

En aquel momento, el trabajo se realizaba en jornadas superiores a las 15 horas diarias en fábricas inhóspitas. Algunos empresarios preferían contratar a mujeres y niños, que planteaban menos problemas laborales. El salario se regía por la ley de la oferta y la demanda, no existía el domingo como día de descanso, y tampoco leyes de previsión social ni sobre accidentes del trabajo. En ciertos casos, las condiciones de las viviendas obreras eran insalubres y favorecían las enfermedades. El estado burgués, imbuido de la ideología liberal, consideraba que toda intervención para solucionar los problemas surgidos entre el capital y el trabajo era inútil, perjudicial e injusta, porque en toda actividad debían respetarse las leyes naturales y no limitar la libertad de los individuos. La aparición de una respuesta revolucionaria a un modelo social injusto era cuestión de tiempo.

La España de la primera mitad de siglo XX, era una nación atrasada y rural, hija de un convulsionado siglo XIX, que la hizo partícipe de varias guerras civiles. Las desamortizaciones eclesiásticas y civiles desarrolladas por los diferentes gobiernos liberales no habían proporcionado una clase media de propietarios agrícolas. Por el contrario, los habían eliminado a favor de las grandes haciendas, especialmente en el feraz sur peninsular. La proletarización de un campesinado empobrecido le obligó a emigrar a las ciudades, como obrero, y desarraigado de sus tradiciones, fue pasto fácil del verbo de los propagandistas revolucionarios de las ciudades dormitorio de la Barcelona y el Bilbao de finales de siglo XIX.

La religión católica había tenido un papel fundamental como eje integrador de la identidad nacional española. Sin embargo, el liberalismo, desde la constitución de 1812, había intentado introducir el concepto de soberanía popular procedente de la revolución francesa. Hasta la instauración del régimen restauracionista, no hubo estabilidad suficiente para sustentar un sistema liberal que admitiese a la Iglesia como parte importante de la sociedad española. La fe católica y el patriotismo español irían de la mano en las formulaciones del magisterio de la Iglesia con un palmario objetivo clerical de hacer interactuar el sentimiento católico y la progresiva conciencia nacional. Pero la Restauración de Cánovas del Castillo había obligado a una tímida apertura al pluralismo religioso. Por ello, la Iglesia se debatió, a lo largo del periodo restauracionista, entre su deseo de ocupar en exclusividad el espacio y las limitaciones que trataba de imponerle un régimen liberal oficialmente tolerante. 
Más aún, la Iglesia española, recuperada de los daños de su primer encuentro con el liberalismo, los religiosos españoles habían conseguido reconstruir sus cuadros aniquilados por los procesos revolucionarios del siglo XIX y con la savia de las nuevas fundaciones podían mirar con optimismo la nueva centuria. Fue el campo de la educación el más importante ámbito de expansión de la Iglesia española. El crecimiento y aumento del número de efectivos de las congregaciones religiosas ayudó sobremanera a ello. En el inicio del siglo XX eran 294 las comunidades religiosas masculinas y 910 las femeninas que se dedicaban a la docencia, en la que se englobaban un tercio de los alumnos de enseñanza primaria y a casi un $80 \%$ de los de secundaria. ${ }^{1}$ En esos años, un pedagogo ilustre, el sacerdote Andrés Manjón, fundador de las Escuelas del Ave María, expresaba el nuevo interés de la Iglesia española por la educación infantil. ${ }^{2}$

En definitiva, se podía decir que en aquel momento, la Iglesia había recuperado su posición de pilar esencial en la sociedad española. No obstante, la Iglesia debía acoplarse a una nueva forma de evangelización, demandada por una clase media urbana y liberal, que solicitaba un catolicismo menos belicista y más conforme con sus nuevos gustos sociales. Las nuevas clases medias, conciliadas con la Iglesia, ayudarían a vertebrar una sociedad católica, según las ideas emanadas de las encíclicas de León XIII y sus sucesores.

A principios de siglo, ya habían llegado a España las teorías de Ketteler, Vogelsang, Mun y La Tour du Pin sobre un corporativismo gremial que volviese a conciliar el interés productor con la división de clases. La cooperación y el respeto entre patronos y trabajadores debían ser los principios capitales para construir la nueva sociedad católica del mundo moderno. Esta dialéctica se enfrentaba tanto a las teorías individualistas liberales como a las estatalistas del marxismo. Con respecto, al régimen liberal, los católicos sociales concebían un papel activo del sindicato con libertad para crearlos los trabajadores y regido únicamente por fines profesionales. El Estado tendría una labor de tutela. Pero el liberalismo concebía que el sindicato alteraba la

\footnotetext{
${ }^{1}$ M. Revuelta, "La Iglesia y la educación: órdenes religiosas docentes; restablecimiento de la Compañía de Jesús en España y sus condicionamientos políticos”, en B. Delgado (Coord.), Historia de la Educación en España y América, vol. 3, Madrid: Fundación Santa María, 1994, pp. 87-94.

${ }^{2}$ Andrés Manjón, nació en Sargentes (Burgos) en 1846. Estudió Derecho en la Universidad de Valladolid, doctorándose con brillantez. Fue catedrático de Derecho Canónico en la universidad de Santiago de Compostela y luego en la de Granada. Se ordenó sacerdote en 1886. Un día volviendo de la universidad, se quedó enseñando a unos niños en la calle. Finalmente, fundó las escuelas del Ave María, con un sistema pedagógico novedoso, para los niños del barrio popular granadino del Albaicín.
} 
relación individual del trabajador con el empresario y propugnaba una posición abstencionista del Estado. Los activistas obreros, tanto socialistas como los anarquistas, concebían al sindicato como instrumento revolucionario para conseguir un cambio político, y la pertenencia a él debía ser obligatorio para todos los trabajadores. La función del Estado sería nula para los anarquistas, partidarios de su abolición, mientras que los de formación marxista le daban un carácter totalitario por su fundamentación filosófica hegeliana.

Como había dicho el Papa en sus encíclicas, Au milieu des solicitudes y Notre consolation, ambas de 1892, el catolicismo debía aplicar el ralliement, la aproximación de la Iglesia y los católicos franceses al régimen de la III República. Con la aceptación de la actividad católica social dentro régimen político liberal, León XIII dio a la Iglesia una doctrina social de la Iglesia adaptada a los tiempos, la Rerum Novarum de 16 de mayo de 1891, que reclamaba una legislación social justa para los trabajadores y llamaba a la cristianización de la sociedad. Los nuevos apóstoles del catolicismo social, habían sido el obispo alemán Ketteler (1811-77) y el político francés Albert de Mun (1841-1914) quienes organizaron en Bélgica, Alemania, Italia y Francia, sindicatos, periódicos y partidos políticos católicos. El ejemplo de los católicos franceses debía ser trasmitido a España, por las posibilidades de éxito en una sociedad mayoritariamente católica, pero que tenía enajenada a una amplia base social católica por su fidelidad a posturas políticas marginadas por el sistema restauracionista, como había pasado con los legitimistas monárquicos franceses. ${ }^{3}$

El tema será, la necesidad de emprender una organización independiente de los partidos dinásticos, conservadores y liberales. La traslación de la división política de los católicos al clero, a la jerarquía e incluso a las propias órdenes religiosas, la subrayaba como la principal causa de la inoperancia del catolicismo hispano. ${ }^{4}$ Los formantes de cualquier organización católica que quisiese mantenerse independiente, procedían del ámbito cultural de los carlistas, integristas y católicos independientes. Estos son los únicos que fuera de la disciplina de los partidos turnantes, estaban dispuestos a actuar de manera conjunta a favor de los intereses católicos frente a los fines de partido. El carlismo, como movimiento legitimista, era más que un partido, al disponer de una extensa organización que agrupaba asociaciones locales, comarcales y regionales de temática cultural, deportiva, juvenil, educativa,

\footnotetext{
${ }^{3}$ J. ROGER, Ideas politicas de los católicos franceses, Madrid: CSIC, 1951; J. RovAN, El catolicismo político en Alemania, Madrid: Instituto de Estudios Políticos, 1964.

${ }^{4}$ V. CARCEL ORTí, León XIII y los católicos españoles, Pamplona: EUNSA, 1988, pp. 19-64.
} 
religiosa y femenina. Su supervivencia en España, en contraste con su drástica desaparición en Francia, fue por su adaptación al catolicismo social, a través de intelectuales como Víctor Pradera. ${ }^{5}$

\section{EL ORIGEN DEL SINDICALISMO OBRERO CATÓLICO}

En el campo laboral, las actividades del catolicismo social se iniciaron desde finales del siglo XIX con los Círculos Católicos del P. Antonio Vicent, a semejanza de los del francés Albert de Mun, pero para principios del siglo XX estos habían fracasado por haberse centrado exclusivamente en el plano religioso, educativo, de mutualidad y ocio, abandonando la actividad sindical. Aunque el jesuita en 1899 proporcionó en el congreso católico de Burgos el primer modelo de estatutos de sindicatos agrarios, tomando como base las ordenanzas de los antiguos gremios de la Corona de Aragón. Los primeros sindicatos agrarios levantinos surgieron, por esa causa, con equipos humanos procedentes de los círculos católicos fundados por el P. Vicent. Aunque inicialmente estos sindicatos, pro su procedencia, tenían como objetivo principal, velar por la moral de sus miembros. ${ }^{6}$

No obstante, no serán la única experiencia realizada en el mundo laboral por católicos sociales. Entre 1916 y 1919 los padres dominicos Gerard y Gafo trabajaron por un sindicalismo puro, formado por obreros, sin intromisiones de los patronos, como había ocurrido en los fundados por el P. Vicent. Los sindicatos debían tener como única finalidad la reivindicación de su mejora profesional, y para exigir sus derechos podían utilizar la huelga y el boicot, aunque no el sabotaje. Para poder atraer a los obreros que habían perdido su religiosidad católica, optaron por la no confesionalidad de los sindicatos. Esta nueva experiencia sindical daría lugar a los Sindicatos Libres Católicos, que se desarrollaron por el norte de España, tomando como base principal la ciudad industrial de Bilbao. ${ }^{7}$

En el otro polo del desarrollo industrial, del norte de España. En las cuencas mineras de Asturias será el canónigo Arboleya quien lleve la misión

${ }^{5}$ J. CANAL, El carlismo. Dos siglos de contrarrevolución en España, Alianza Editorial, Madrid, 2000; J.L. ORElla, Víctor Pradera. Un católico en la vida pública de principios de siglo, Madrid: BAC, 2000

${ }^{6}$ J. Andrés-Gallego, Pensamiento y Acción social de la Iglesia en España, Madrid: Espasa Calpe, 1984, pp. 241-243.

${ }^{7}$ E. GonZÁlez, José D. Gafo Muñiz, OP. (1881-1936). Por la concordia en España, Salamanca: Ed. San Esteban, 2009. 
de crear los sindicatos independientes mineros, que en su momento inicial tuvieron más importancia que el vinculado a la UGT (socialista). Sin embargo, sus reivindicaciones profesionales le llevaron al enfrentamiento con la patronal minera, que quería eliminar su tono reivindicativo, y por su carácter católico, también con el sindicato socialista. Finalmente, la conjunción de ambas fuerzas, consiguió el declinar de la labor de Maximiliano Arboleya, que fue uno de los más avanzados de los pioneros sindicales católicos. ${ }^{8}$

En cuanto a la zona mediterránea, la historia del sindicalismo católico cuenta con su propia realidad. Sus antecedentes están en la Acción Social Popular del P. Palau que tuvo que disolverse en 1919. El ambiente creado por la ASP proporcionó una serie de personas que se sintieron en la obligación de crear una serie de sindicatos católicos, que en ese mismo año, decidieron agruparse en una confederación nacional. La mayor parte eran sindicatos confesionales fundados bajo la orientación de los jesuitas y con el apoyo del marqués de Comillas. La resultante Confederación Nacional de Sindicatos Católicos, no obstante, no reunió a todos los sindicatos del ámbito católico, como había sido su finalidad. Los Sindicatos Católicos Libres del norte de España, mantuvieron su independencia orgánica, para evitar la posible influencia dominante de los sindicatos procedentes del patrocinio del marqués de Comillas.

Pero, en Barcelona, la situación variaba. Los únicos sindicatos que habían sido fundados por obreros católicos, fueron los Sindicatos Libres de Cataluña. Ramón Sales, su fundador e inspirador, había movilizado a los trabajadores simpatizantes del carlismo para crear los Sindicatos Libres. La nueva organización sindical se incorporó a la reivindicación de la mejora de las condiciones laborales, desde la independencia de toda organización política, la no confesional, y la ausencia de todo tipo de patrocinio procedente de la patronal catalana (Fomento Nacional del Trabajo). Su fundación fue importante, porque rompió el monopolio sindical ejercido por el sindicato único de la CNT. Este hecho obligó a los radicales del anarquismo al ataque directo contra los libres, por dividir el frente proletario. Ambas organizaciones ensangrentarán las calles condales, con el asesinato masivo de sus miembros y simpatizantes, a través de una espiral de violencia provocada, por la acción directa y la represalia en venganza. ${ }^{9}$ Pero será en el ámbito agrario, donde el catolicismo social demostrará una gran feracidad.

\footnotetext{
${ }^{8}$ D. BenAVIDES, Maximiliano Arboleya. Un luchador social entre las dos Españas, Madrid: BAC, 2003.

${ }^{9}$ C. Winston, La clase trabajadora y la derecha española (1900-1936), Madrid: Cátedra, 1989.
} 


\section{EL ORIGEN DEL AGRARISMO CATÓLICO}

El mundo rural español era muy precario, por sus propias características, pendiente de la climatología, y por la desaparición de comunales en las desamortizaciones liberales. La necesidad crediticia para comprar simientes y aperos, que se reembolsarían con el pago por las cosechas, hacía del campesinado, un objetivo de usureros y prestamistas. La necesidad de crear sociedades de socorro, cajas de ahorro y cooperativas, proporcionará el primer objetivo práctico para la divulgación del asociacionismo católico agrario. Sin embargo, las grandes diferencias del campo español determinarán su implantación. En el sur, territorio de grandes haciendas trabajadas por jornaleros sin tierras, carentes de lo más mínimo para vivir. Era casi imposible poder organizar algo, por la carencia de medios del campesinado y la oposición de los propietarios. Por el contrario, en la mitad norte, donde perduraba la pequeña y mediana propiedad, los labradores podían adelantar pequeñas cantidades para la entidad crediticia que les asociaba. Además, en aquellas provincias, las asociaciones revolucionarias todavía no tenían presencia y la práctica religiosa era mayoritaria. La abundancia vocacional del clero español provenía de la mitad norte de la península ${ }^{10}$.

Un hecho favorable fue la ley de sindicatos agrícolas del 28 de enero de 1906 , que favorecía su fundación con desgravaciones fiscales y ayudas económicas. Las nuevas sociedades agrupaban a propietarios y arrendatarios, y a diferencia de los sindicatos obreros urbanos, que reunían exclusivamente a trabajadores, y tenía como objetivo la defensa de sus intereses. Los agrícolas tenían una función cooperativista, como era la compra de abonos y simientes, adquisición de maquinaria, almacenamiento, venta de productos y sociedades de crédito. Para su implantación fue determinante la labor que los curas párrocos llevaron a cabo.

El principal modelo desarrollado fue el de las cajas de préstamo Raiffeisen, organizadas por Friedrich Wilhelm Raiffeisen, basada en el principio de la solidaridad ilimitada de todos los socios a la hora de responder con sus bienes de los componentes adquiridos. Hombre de una gran formación cristiana, en su modelo el clérigo era persona fundamental en la gerencia de la institución. Este modelo fue conocido y divulgado en España por Joaquín Díaz de Rábago, en su obra Crédito agrícola: Las Cajas rurales de préstamos

\footnotetext{
${ }^{10}$ M. Revuelta, Historia de la Compañía de Jesús en la España Contemporánea, vol. II, Santander: Mensajero, 1991.
} 
Sistema Raiffeisen, en 1894. Director de la sucursal del Banco de España en Santiago, e impulsor de iniciativas económicas en la ciudad gallega, era también miembro de las conferencias de San Vicente Paúl. Díaz de Rábago junto al zamorano Luis Chaves, quien también escribió y ayudó a la creación en su provincia de cajas rurales del tipo Raiffeisen. Los primeros focos antes de la ley de 1906 serán Murcia. Navarra, Levante y Zamora. ${ }^{11}$

En Murcia será Nicolás Fontes el pionero, quien, preocupado por la miseria rural, iniciará una labor de creación de cajas rurales con decuriones, responsables de diez familias y centuriones, que en la temprana fecha de 1901, tenía presencia en 12 localidades con 5.436 socios. Dos de aquellas entidades estaban en los seminarios de Murcia y Chinchilla, para que los futuros sacerdotes se formasen en su práctica y la impulsasen en sus futuras parroquias. ${ }^{12}$

Con el modelo legal creado en 1906, y a una fuerte demanda social, se le sumó la preparación de sus divulgadores. La principal propaganda a su favor se inició en la Asamblea diocesana de las Corporaciones Católico-Obreras de Tarazona en 1904, la de Menorca, Valencia y Palencia en 1905. Al año siguiente, se ampliaba la información en

las Asambleas diocesanas de Pamplona y Zaragoza; en 1907 continuó con la Asamblea regional de Granada y también de la labor paralela de las Semanas Sociales de Madrid, Valencia y Sevilla, en 1906, 1907 y 1908. En aquellas reuniones se habían repartido más de 12.000 ejemplares de los estatutos modélicos para los Sindicatos Agrícolas, escritos por el P. Vicent. Sí en 1906 se podían constatar unos 50 sindicatos, tres años después se había pasado de 500 agrupaciones. En 1907, 17 de las asociaciones eran valencianas y otras 37 navarras, haciendo de estas provincias sus dos puntos neurálgicos iniciales.

La primera Caja Rural española había sido la de Amusco, en Palencia, en 1900. Pero Castilla despertará más tarde. Dos años después, un joven cura navarro, Victoriano Flamarique, leyó un folleto del pionero social zamorano Luis Chaves Arias sobre las Cajas Raiffeisen. En Navarra la primera caja rural navarra había sido en Tafalla, en 1902, por la labor de Atanasio Mutuverría. Dos años después, Victoriano Flamarique constituyó la de Olite. Poco después, el obispo J. López-Mendoza encargó a Victoriano Flamarique y al también sacerdote Antonio Yoldi, la difusión de aquel modelo a seguir. El

${ }^{11}$ S. MARTínez y A. PASCUAL, "Los pioneros del cooperativismo agrario del crédito español (1880-1920)", CIRIEC-España 2008, no 63, pp. 89-112.

${ }^{12}$ N. Noguer, Las cajas rurales en España y en el extranjero. Teoría, historia, guía práctica, legislación, estatutos, formularios, Madrid: Razón y Fe, 1912, pp. 556-557. 
propio Flamarique partió a La Rioja, para extender el modelo allí. ${ }^{13}$ Desde 1907, en la diócesis de Calahorra, el asociacionismo agrario había entrado a través de Francisco La Fuente, misionero de Corazón de María, que sería relevado por Félix Aguado, cuando fue como misionero a Colombia en 1909. Para entonces, el P. La Fuente había convocado una reunión en Santo Domingo de la Calzada, con el abad de la catedral, Juan Villaverde, algunos sacerdotes y laicos, de 16 pueblos de la comarca. Sí en 1909 eran siete los Sindicatos riojanos, se elevarían a 93 en 1914.

Mientras en Zamora seguía su labor Luis Chávez, en Salamanca, era el profesor de sociología del Seminario salmantino Juan Francisco Morán, quien llevó la labor. En la Montaña cántabra, era terreno del sacerdote Anselmo Bracho, fundador de la Asociación de Labradores de Ruiseñada, en 1907. En ese año, el cura había fundado doce sindicatos locales, que llegarían a 45 en 1911. Pero la gran ayuda procedería de la llegada del jesuita palentino Sisinio Nevares, a la residencia de Carrión de los Condes, quien junto a Antonio Monedero, un importante labrador de Dueñas, se convirtieron en los principales fundadores de la provincia. Aunque, como en el resto de los sitios, la primera labor de roturación la habían llevado sacerdotes como Anacleto Orejón, Gregorio Amor y Valentín Gómez. ${ }^{14}$ En 1913, la Federación palentina estaba formada ya por 72 Sindicatos; y en 1914 eran ya 99 agrupaciones.

Con respecto a Ciudad Rodrigo, la iniciativa personal fue llevada directamente por el obispo Ramón Barberá, que en su primer año, en 1908, consiguió la fundación de 24 sindicatos. En Astorga, fue parecida la labor, gracias al obispo Julián de Diego y Alcolea. En su región había en 1909 seis Sindicatos, que en 1913 habían pasado a ser medio centenar. Finalmente, en la Asamblea conjunta que celebraron las ocho Federaciones Agrarias Católicas que había en León y Castilla en 1914, estuvieron representados 650 Sindicatos, que sumaban entre 150.000 y 200.000 miembros cooperativos. ${ }^{15}$

\footnotetext{
${ }^{13}$ A. PAzos, "Teoría y acción en los pioneros del catolicismo social navarro (1891-1912)”, en XII Simposio Internacional de Teología, Pamplona: UNAV, 1991, pp. 255.

${ }^{14}$ J.M. CuEnCA TORIBIO, Sindicatos y partidos católicos españoles: ¿Fracaso o frustración? 1870-1077, Madrid: Unión Editorial, 2001, pp. 40-47

${ }^{15}$ J. ANDRÉs Gallego, Pensamiento y Acción social de la Iglesia en España, pp. 262-275.
} 


\section{EL AGRARISMO CATÓLICO EN CASTILLA}

En Castilla-León los intereses agrarios se habían convertido en el leit motiv de la razón de la organización de los católicos castellanos, y Palencia fue su principal epicentro. Una de las principales acciones fue cuando el 5 de mayo de 1912, se reunieron en la plaza de toros de Palencia un millar de labradores y representantes de distintas agrupaciones agrarias católicas de la provincia. Además de los discursos que traslucían las reivindicaciones del frágil mundo campesino, como fueron las palabras de Pedro Carrancio, presidente de la cámara agraria de Carrión de los Condes. También hubo necesidad de interpretar aquella reunión masiva de labradores en un tono más elevado que la simple demanda ante los arriendos, las malas cosechas o mayores protecciones ante las tarifas y embargos. Esta labor fue llevada por Ángel Herrera, quien acusó al gobierno de ser responsable de crear el ambiente propicio entre la clase social más amplia del país para una revolución, cuando los labradores eran el elemento sano que podía regenerar a España. Pero para esto, los labradores no debían abandonarse y tenían que fundar sindicatos y asociaciones católico-agrarias que se federarían a nivel provincial para conseguir fuerza social. ${ }^{16}$

Pero el éxito obtenido en Palencia con el gran acto católico agrario pronto tendrá repercusión mimética en otros lugares. En Alba de Tormes se van a congregar unos cinco mil labradores salmantinos que se van hacer eco de las reivindicaciones de protección del mundo rural. En el mitin los oradores exponen que la masa campesina es católica y la miseria del campo proviene del mal gobierno del liberalismo. En ese sentido, el ganadero salmantino, José Lamamié de Clairac habló de la necesidad de fundar un sindicato agrario para remediar los males del campo. El acto concluyó con la aceptación de las conclusiones de Palencia y la necesidad de fundar y federar a las distintas asociaciones católico-agrarias de Salamanca.

Antonio Monedero, presidente de la federación católico-agraria de Palencia, y que pronto se convertirá en el líder del agrarismo católico español, junto al jesuita P. Sisinio Nevares, desarrollaron una labor organizativa que en cinco meses, desde el gran acto que se dio en Palencia capital, les llevó a fundar veinte sindicatos agrarios en diferentes localidades de la provincia, gran parte de ellos con su caja rural y cooperativa. La primera ya había prestado un millón de pesetas de la época en créditos y la organización social abarcaba a diez mil labradores de la provincia, además de disponer de su

\footnotetext{
${ }^{16}$ Los discursos de la jornada aparecen en El Debate, del 6 y 7 de mayo de 1912.
} 
propio medio informativo el Boletín de Acción Social Católica-agraria de la Federación Palentina. El pequeño rotativo se hizo eco de todas las andanzas de Antonio Monedero y del P. Sisinio Nevares, verdaderos protagonistas del apostolado rural.

La labor se hacía muchas veces dura, tan pronto había que estar recorriendo el norte de Palencia, como se pasaba la muga con la montaña cántabra y a golpe de casco de caballerizas se llegaba a pueblos remotos donde la consecuencia de las palabras del recién llegado, invitado por el párroco, era la fundación de un sindicato, una caja rural y una cooperativa. Los viajes del P. Sisinio Nevares y Antonio Monedero serán retratados por el periodista Juan Hidalgo, de la siguiente y sugerente manera:

eran estos propagandistas sociales nuevos caballeros andantes, tocados, a los ojos del mundo, de algún género de locura, e imaginaba que tales locos como éstos eran los que hoy se necesitaban en la tierra, hombres dominados por una idea, enamorados de ella, chiflados por Dios, según la gráfica expresión del arcipreste de Huelva; que fueran por esos campos y esos valles de Dios avivando la fe e inflamando la caridad de los hijos del trabajo, los predilectos de la Iglesia. ${ }^{17}$

El catolicismo agrario se había encumbrado como uno de los pilares del catolicismo social. La importancia del mundo rural en el plano social y económico de la España de entonces era capital. Bajo el patrocinio del diario nacional El Debate se reunieron delegados de numerosas asociaciones agrarias católicas. Los protagonistas de la asamblea fueron los principales pioneros de la experiencia, Antonio Monedero y el jesuita Sisinio Nevares. ${ }^{18}$ Ambos palentinos desarrollaron y compartieron sus conocimientos. El asociacionismo católico agrario era el único que podía frenar la difusión del socialismo por el mundo rural. Pero para asegurar el triunfo de la operación, los pueblos seleccionados debían estar libres de presencia socialista o anarquista. De esta manera, con la complicidad del párroco, se podía llevar una buena labor de información y concienciación, pasando a continuación a fundar la agrupación agraria.

Aunque la presencia era numerosa, las provincias donde la labor católicaagraria había cobrado un fuerte protagonismo en Castilla, era en concreto, Palencia, Segovia, Valladolid, Zamora, Santander y Soria; y también en Galicia, aunque aquí, los ganaderos organizados provenían de Lugo y La Coru-

\footnotetext{
${ }^{17}$ El Debate, del 15 de octubre de 1912.

${ }^{18}$ M. Revuelta, "El P. Sisinio Nevares. Etapas de su acción social y promoción de los sindicatos agrarios palentinos", Publicaciones del Instituto Tello Téllez de Meneses 2005, nº 76, pp. 355-393.
} 
ña. Aunque en las asociaciones se prohíbe la presencia de propietarios que no vivan del campo, en su mayor parte están compuestas por propietarios, arrendatarios, algún jornalero y el cura. Los puntos a tratar de la asamblea solían ser de carácter reivindicativo y organizativo. Esencialmente la labor de expansión de las cajas de ahorros y montes de piedad, muy necesarias para encauzar el ahorro y el crédito con un bajo interés.

Sin embargo, en Palencia, la cuna del catolicismo agrario, el rotativo creado por Antonio Monedero, el Boletín de Acción Social Católica-agraria de la Federación Palentina, pasó a ser el órgano de toda la federación castellana, abarcando Santander, Logroño, León, Palencia, Burgos, Soria, Valladolid, Zamora, Salamanca, Ávila y Segovia. El boletín intentaba ser un medio informativo que abarcase todos los aspectos de interés del labrador, de esta manera, comprendía: Sociología católica, Agricultura práctica, Acción general, Acción particular de las provincias, Consultas y correspondencia, Bolsa de trabajo; Compras, ventas e intercambios, y Concursos.

La importancia del desarrollo emprendido por el catolicismo agrario se veía en auge en aquellos pueblos donde su vida tradicional no se había visto perturbada por la acción de socialistas, ni anarquistas. La fundación de sindicatos se veía acelerada y favorecida por el intenso catolicismo de los labradores y el apoyo de los párrocos. Los labradores se sumaban a la iniciativa emprendida por los católicos sociales, cuando contaban con la conformidad del párroco, quien les daba una garantía de la seriedad de la labor divulgada en su localidad. De esta manera, la labor de los sacerdotes se hacía fundamental para la futura expansión del asociacionismo agrario, por el liderazgo social que tenían los sacerdotes en el pueblo.

La hoja de ruta del líder de los labradores católicos, Antonio Monedero, era estimular la integración de los labradores en los sindicatos locales, y que estos a su vez se federasen a nivel provincial. De esta forma, la suma de esfuerzos conseguía articular una fuerza social considerable en defensa de los intereses de un campesino depauperado. El ejemplo era la propia Palencia, donde Antonio Monedero había conseguido para 1914, federar a 93 sindicatos locales, representativos de treinta mil labradores. Una fuerza social considerable, e independiente de los partidos políticos dinásticos. En 1917 la confederación agraria castellano-leonesa, reunía 21 federaciones, un millar de sindicatos y 200.000 labradores. ${ }^{19}$ El catolicismo social agrario tenía una base social importante para ayudar a formar ese pueblo católico que la jerarquía católica quería recuperar en España, a semejanza de otros países europeos.

\footnotetext{
${ }^{19}$ El Debate, del 25 de febrero de 1917.
} 
La importancia desarrollada por las actividades del catolicismo social en España se hacían eco en las palabras y apoyo recibido del cardenal Primado de Indias, Gregorio Aguirre, quien no sólo había impulsado diferentes campañas y mítines, sino que había apoyado la federación de las obras católicosociales, fuesen agrarias u obreras, a través del Consejo nacional de las corporaciones católico-obreras. El cardenal Aguirre fue quien, ante el impulso del gobierno de imponer escuelas laicas sin testimonio religioso, vio la necesidad de encuadrar a los maestros y fundar asociaciones de maestros católicos que se federasen luego a nivel nacional. Su labor fue seguida por su sucesor, el cardenal Victoriano Guisasola, quien fundó un secretariado nacional agrario en 1915, en la persona de Maximiliano Arboleya, No obstante, su labor de centralización tuvo la oposición del P. Nevares y de Monedero, no consiguiendo la confederación a nivel nacional hasta $1917 .{ }^{20}$ Los palentinos estaban en contra de un proceso de confederación, donde las federaciones iban a quedar en manos de la directiva del secretariado, nombrada por el cardenal, y compuesta por aristócratas conservadores y profesores universitarios católicos sociales de ascendencia carlista. Cuando se formó la Confederación Nacional Católico Agraria, su presidente fue Antonio Monedero (Palencia); vicepresidente Luis Díez de Corral (La Rioja); tesorero, José M. Aristizábal (Ciudad Rodrigo); Secretario Rafael de las Heras (Valladolid; vocales, Esteban Deán, Joaquín Ballester, Rafael López, Andrés Pellón y Félix Burriel (Castillo 1979: 102).

El mandato de Monedero duró hasta 1921, cuando fue depuesto por el excesivo gasto que la organización central iba teniendo, aunque en realidad, la causa venía derivada por sus continuos enfrentamientos con Severino Aznar y su equipo. Dos años después el palentino fundaba la Liga Nacional de Agricultores, como elemento afín a los sindicatos libres, y en rebeldía a los elementos dirigentes de la CNCA. Durante su mandato el crecimiento fue espectacular, si en 1914 eran doce federaciones con 500 sindicatos y 150.000 miembros aproximadamente; en 1920, eran 59 federaciones que agrupaban a 5.000 sindicatos y más de 600.000 socios cooperativistas. $^{21}$

\footnotetext{
${ }^{20}$ D. Benavides, Maximiliano Arboleya, pp. 240-246.

${ }^{21}$ J.J. Castillo, Propietarios muy pobres, Madrid: Ministerio de Agricultura, 1979, p. 115.
} 


\section{EL AGRARISMO SOPORTE DEL CATOLICISMO SOCIAL}

Posteriormente la CNCA fue languideciendo por ausencia de un fuerte liderazgo, y por el cambio de régimen que significó la instauración en 1923 de la dictadura del general Miguel Primo de Rivera. El pronunciamiento de Primo de Rivera respondió a una situación de crisis política generalizada. Los móviles que habían empujado al ejército a cometer esta acción los justificaba según su opinión: Los asesinatos sindicales, el desorden y el nepotismo en la administración, la sangría de Marruecos, el nacionalismo independentista, la inmovilidad vigente, las necesarias reformas siempre aplazadas y el caciquismo fueron por si mismas causas suficientes que justificaron, por interés nacional, una acción que fue ilegal. Sin embargo, el régimen de fuerte ejecutivo, aunque modernizó el país con una política de obras públicas y restauró el orden, poniendo fin a la guerra de Marruecos, no puso eludir la crisis de 1929, que acabo llevándose al régimen junto con la monarquía.

Cuando el 14 de abril de 1931 se proclamó la República, la cuestión religiosa no se planteó. La Iglesia aceptó el cambio de régimen y reconoció a las nuevas autoridades. Sin embargo, los días 11, 12 y 13 de mayo de 1931 en Madrid, Valencia, Alicante, Murcia, Sevilla, Málaga y Cádiz se produjeron el incendio y saqueo de numerosos conventos y colegios religiosos, ante la pasividad de las fuerzas de orden público. Las nuevas autoridades republicanas, influidas por ideales laicistas, que se plasmarían en la célebre frase de Manuel Azaña: "España ha dejado de ser católica", confirmaría la incompatibilidad del catolicismo con el republicanismo. La constitución de 1931 aprobaba una serie de medidas contrarías a la presencia de la Iglesia en el mundo educativo, y prohibía la presencia de la Compañía de Jesús en territorio español. Del mismo modo, el cardenal Segura, Primado de Toledo; y monseñor Múgica, obispo de Vitoria, se veían expulsados de sus sedes episcopales por decisión del gobierno republicano. La vertebración de la ciudadanía católica en un movimiento político que defendiese la igualdad cívica de los católicos, se hizo tan necesaria como había pasado en la Alemania imperial de Bismarck.

Los antecedentes intelectuales ya habían surgido antes. La necesidad de contrarrestar la acción revolucionaria de los socialistas provocó que varios intelectuales decidiesen formar un núcleo doctrinal que sirviese de laboratorio de ideas. Su carácter ideológico marcó su pequeño número de miembros, veinticinco en su momento inicial, que nunca pasó de cuarenta, como marcaba el artículo IV de sus estatutos. El grupo "Democracia Cristiana" contó 
desde un principio con el apoyo y protección del cardenal Guisasola' primado de Toledo, que siempre tuvo una gran preocupación por los temas sociales.

El grupo desde su origen, no pretendió ser base de ningún partido político, sino difundir y hacer presente los principios sociales del catolicismo en la sociedad española. El grupo surgirá en Zaragoza, ciudad adelantada del catolicismo social. La celebración en Madrid, del primer congreso de sindicatos católicos en abril de 1919, planteará la necesidad de organizar el mundo obrero, después del impacto causado por la revolución bolchevique en Rusia. Sin embargo, esta acción social que se desarrollaba no podía realizarse completamente sin el respaldo y guía de un grupo intelectual. Los intelectuales que más habían marcado el congreso sindicalista con su presencia serían los que formarían el grupo "Democracia Cristiana". Entre ellos destacará Severino Aznar, que será el presidente del grupo; Amando Castroviejo e Inocencio Jiménez, que se convertirán en sus vicepresidentes; Álvaro López Núñez, como bibliotecario y censor; Pedro Sangro y Ros de Olano, tesorero; Antonio Maseda, secretario; y como vocales, Maximiliano Arboleya Martínez, Juan Zaragüeta y Leopoldo Calvo Sotelo. ${ }^{22}$ Además de estos nombres de su junta directiva, destacarían otros como Salvador Minguijón, quién era uno de los más conocidos en el ámbito católico a través de sus artículos en El Debate. ${ }^{23}$

Severino Aznar era el más destacado del grupo por su antigua actividad política en el carlismo aragonés y como la persona más versada en previsión social, por sus estudios y viajes al extranjero. ${ }^{24}$ Salvador Minguijón e

\footnotetext{
${ }^{22}$ M.M. LóPEz COIRA, El pensamiento social de Severino Aznar 1870-1959, Madrid: Universidad Complutense, 1986, p. 66.

${ }^{23}$ El manifiesto fundacional del grupo Democracia Cristiana, que apareció en las páginas de El Debate, entre el 7 y el 14 de julio, será firmado por: Gregorio Amor, canónigo de Valladolid; Ramón Albó y Martí, abogado; Maximiliano Arboleda, canónigo de Oviedo; Severino Aznar, catedrático de la Universidad de Madrid; José María Boix, Dir. de la Revista Social; José Calvo Sotelo, diputado maurista; Amando Castroviejo, catedrático de Santiago; Juan Francisco Correas dir. de “Acción Social” de Jaén; Daniel García Hugues, canónigo del seminario de Madrid; Gerardo Gil, agustino y profesor en la Universidad de El Escorial; Juan de Hinojosa, publicista; Bruno Ibena, agustino; Inocencio Jiménez, catedrático de la universidad de Zaragoza; Luis de Jordana, catedrático de la universidad de Valencia; José Latre "Le Brun", publicista; Álvaro López Núñez, secretario general del Instituto Nacional de Previsión; José Llovera, catedrático del seminario de Gérona; Salvador Minguijón, catedrático de la universidad de Zaragoza; Juan Francisco Morán, canónico del seminario de Madrid; Daniel Pla y Daniel, expresidente de Acción Social Popular; Juan Reig y Genovés, del Instituto de Reformas Sociales; Pedro Sangro y Ros de Olano, del Instituto de Reformas Sociales; José María Zumalacárregui, catedrático de la universidad de Valencia.

${ }^{24}$ Severino Aznar fue de extracción popular y rústica, tuvo una formación religiosa, tradicional y militante en el carlismo. En 1906, Severino Aznar funda la "Paz Social", organismo que sirvió para estimular la fundación de sindicatos católicos agrarios y cajas rurales para su financiación. En 1914, su interés por la justicia social le llevó a ser asesor social del Instituto Nacional de Previsión,
} 
Inocencio Jiménez formaban parte del núcleo de intelectuales zaragozanos vinculados al catolicismo social y eran catedráticos de su universidad. Álvaro López Núñez, era el secretario general del Instituto de Previsión Social. Maximiliano Arboleya Martínez, sacerdote muy conocido por ser el fundador de los sindicatos católicos de mineros en Asturias.

Todos ellos, junto a otro participaron de forma activa en la divulgación de los principios del catolicismo social por toda la geografía nacional, dando lugar a diferentes fundaciones asociativas que vertebrarían ese plural y complejo movimiento. Durante el periodo republicano, 1931-1936, la fuerza del catolicismo agrario fue fundamental para estructurar el político. Aunque la CNCA había ido declinando su inicial empuje, aún podía reunir según sus fuentes en 1933: 38 federaciones, con 1.902 sindicatos y 253.428 socios; que en 1935 serían 38 federaciones, con 1.869 sindicatos y 180.555 socios. $^{25}$

De esta manera, se demostraba de nuevo que la conjunción de fuerzas de las distintas organizaciones católicas existentes podía sacar del marasmo y de la pasividad a una mayoría social católica que pervivía silenciosa votando a un partido que no llenaba sus expectativas y que se contentaba con mantener en listas electorales algún candidato de clara militancia católica. Con la república hubo el momento propició de aprovechar ese momento, y fue por eso que en 1933 nació la CEDA (Confederación Española de Derechas Autónomas), que con sus 736.000 miembros fue la mayor organización de derechas conocida en España. Este movimiento nacía bajo la inspiración del catolicismo social y fue vertebrado por gente procedente de asociaciones seglares de la Iglesia, de donde se alimentaba electoralmente. Con este sello, el mensaje social que la Iglesia llevaba tiempo divulgando tenía al fin un portavoz político para llevarlo a cabo. Acción Popular, era el partido central, al cual se le iban asociando organismos regionales o sectoriales, como Derecha Regional Valenciana o Acción Obrerista, respectivamente. ${ }^{26}$

La influencia de la CNCA era palpable en la CEDA. Su presidente José María Gil Robles, había sido el secretario de la CNCA en Salamanca, al que se podían unir otros 16 nombres de directivos de asociaciones vinculadas

donde desarrollará una gran labor defendiendo las reivindicaciones obreras y denunciando las críticas situaciones en que se encontraban algunos trabajadores. En 1921, conquistó la cátedra de Sociología de la Universidad Central, jubilándose en 1940. Después, entrará como miembro en la Real Academia de las Ciencias Morales y Políticas, y emprenderá numerosos viajes, participando en congresos, como los Congresos Mundiales de la Población de Ginebra de 1927 y Roma de 1931, donde defendió las teorías de la Iglesia contra las propuestas malthusianas de los liberales.

${ }^{25}$ J.J. CASTILlO, Propietarios muy pobres, p. 299.

${ }^{26}$ J.M. CUENCA TORIBIO, Sindicatos y partidos católicos españoles, pp. 127-163. 
con la CNCA. Otros cuatro directivos de la CNCA estaban vinculados al carlismo, que había adoptado el catolicismo social en su discurso como medio de modernización de su discurso. ${ }^{27}$ Como partido con posibilidades de gobierno, la CEDA tenía una estructura más consolidada y mayor número de secciones que el resto de los partidos de la derecha. De este modo, podía reclutar y componer equipos especializados con personas vinculadas al catolicismo social. Entre los cuales muchos se encumbrarían en la administración del régimen posterior, como José Larraz López, Alberto Martín Artajo y Pedro Gamero del Castillo. ${ }^{28}$

En cuanto a medidas económicas, la CEDA fomentaba el nacionalismo económico al propugnar la españolización de las empresas de interés nacional, procurando que estuviesen en manos de españoles o hispanoamericanos. Del mismo modo, el Estado debería intervenir en proteger arancelariamente los intereses trigueros, prohibiendo la importación de cereales panificables para evitar una caída del precio. La CEDA, como el resto de la derecha centraba su política económica en la agricultura. De 115 diputados en 1933, 30 eran conservadores y se alineaban junto a los propietarios agrarios, 50 se mantenían neutrales y seguían la consigna del Gil Robles, y los 35 restantes sostenían las directrices de Giménez Fernández, quien sería el polémico ministro de Agricultura de la CEDA, que defendió un atrevido proyecto de reforma agraria ${ }^{29}$.

\section{AGRARISMO CATÓLICO Y GUERRA CIVIL}

Cuando en 1936 el frente popular, una amplia coalición de partidos de izquierda, ganó las elecciones generales, las persecuciones contra los católicos arreciaron e incluso se cerraron periódicos vinculados a la derecha y se ilegalizaron algunos partidos políticos. E1 18 de julio de ese año, una parte minoritaria del ejército se sublevó contra el gobierno republicano, y sin el inmediato apoyo civil que recibió, no hubiese podido hacerse con el control de un tercio del territorio nacional.

Durante la guerra civil, la CNCA, mantendrá su poderoso influjo bajo el liderazgo del presidente de la Federación Agraria Salmantina, José María

\footnotetext{
${ }^{27}$ J.J. CASTILlo, Propietarios muy pobres, pp. 272-273.

28 J.R. Montero, La CEDA. El catolicismo social y político en la II república, vol. 1-2, Madrid: Ministerio de Trabajo, 1977, pp. 739-745.

${ }^{29}$ Ibid., p. 186.
} 
Lamamié de Clairac, importante dirigente carlista, perteneciente como número dos a la Junta Nacional de Guerra, una especie de gobierno carlista a la sombra bajo el liderazgo de Manuel Fal-Conde, y Presidente del Banco de Crédito Local. Por tanto, la CNCA contaba con la protección de los carlistas, ante la desaparición de la CEDA, para el mantenimiento de sus posturas defensivas ante el asimilacionismo que demostrarían los falangistas desde el ministerio de Agricultura y el Consejo nacional de sindicatos.

La importancia del pequeño propietario agrícola para los militares alzados, quedaría demostrada por la fundación del Servicio Nacional del Trigo, que con el dirigismo llevado por los falangistas del departamento de Agricultura, tenía la responsabilidad de mantener el abastecimiento de un alimento básico a precio moderado para los consumidores y unos ingresos regulares para los productores ${ }^{30}$. La superproducción de 1937 conllevaba en un sistema liberal la caída de los precios del trigo y la ruina para una parte importante de los agricultores propietarios de la meseta ${ }^{31}$. Sin embargo, la actuación del Servicio Nacional del trigo, permitía salvaguardar los ingresos de los labradores al mantener ficticiamente sus ingresos con la compra a un precio tasado de la cosecha, guardando el Estado el excedente del grano producido. De este modo, el agricultor podía contar con un ingreso seguro y aseguraba su nivel de vida.

Había que tener en cuenta, que las federaciones rurales agrupadas en la CNCA, reunían una parte importante del capital humano y económico de Castilla-León, Aragón, La Rioja y Navarra. Este peso del catolicismo social agrario había tenido su paralelismo en la política, de forma mayoritaria en la CEDA, y en menor medida, en el carlismo. En la Guerra Civil, los militares sublevados se dieron cuenta que la zona dominada en un primer momento por sus allegados, coincidía geográficamente, casi pueblo por pueblo, con la controlada por las asociaciones agrarias católicas y que su apoyo popular dependía fundamentalmente de esta capa social. Las medidas sociales y económicas emanadas por la Junta Técnica y posteriormente por el Gobierno Nacional, debían beneficiar a este sector social, clave en el apoyo popular a los nacionales. Aunque la CNCA acabo siendo absorbida por la institución sindical del régimen.

Algunos de sus dirigentes ocuparon cargos de responsabilidad en el futuro régimen como José María Fernández Ladreda, jefe de la CNCA asturiana

\footnotetext{
${ }^{30}$ J.J. CASTILlO, Propietarios muy pobres, p. 399.

${ }^{31}$ E. MALEFAKIS, "La Economía española y la guerra civil", en J. Nadal, A. Carreras y C. Sudriá, La Economía española en el siglo XX, Madrid: Ariel, 1987, pp. 150-163.
} 
y Luis Alarcón de la Lastra, miembro de la CNCA y diputado por la CEDA de Sevilla en 1933, quienes participaron como oficiales de artillería durante la guerra y luego como ministros. El primero fue ministro de Obras Públicas y el segundo de Industria ${ }^{32}$. Una de las consecuencias de su importancia será que el régimen evolucionase hacía un sistema autoritario de derechas, pero no a un totalitarismo de signo fascista.

\section{BIBLIOGRAFIA}

ANDRÉS-CAllego, José. Pensamiento y Acción social de la Iglesia en España. Madrid: Espasa Calpe, 1984.

Benavides, Domingo. Maximiliano Arboleya. Un luchador social entre las dos Españas. Madrid: $\mathrm{BAC}, 2003$.

CANAL, Jordi. El carlismo. Dos siglos de contrarrevolución en España. Madrid: Alianza Editorial, 2000.

CARAsa Soto, Pedro. "El crédito agrario en España durante la Restauración. Entre la usura y el control social." En Estudios sobre capitalismo agrario, crédito e industria en Castilla, coord. Bartolomé Yun. Salamanca: Junta de Castilla-León, 1991, pp. 289-343.

CARCEl OrTí, Vincente. León XIII y los católicos españoles. Pamplona: EUNSA, 1988.

Castillo Alonso, Juan José. Propietarios muy pobres. Madrid: Ministerio de Agricultura, 1979.

Cuenca Toribio, José Manuel. Sindicatos y partidos católicos españoles: ¿Fracaso o frustración? 1870-1077. Madrid: Unión Editorial, 2001.

GonzÁlez LóPez, Etelvino. José D. Gafo Muñiz, OP. (1881-1936). Por la concordia en España. Salamanca: Ed. San Esteban, 2009.

LÓPEZ COIRA, María Mercedes. El pensamiento social de Severino Aznar 1870-1959. Madrid: Universidad Complutense, 1986.

MALEFAKIS, Edward. La Economía española y la guerra civil. En Jordi Nadal Lorenzo, Albert Carreras i Odriozola y Carles Sudrià. La Economía española en el siglo XX. Madrid: Ariel, 1987, pp. 150-163.

Martinez-Rodriguez, Susana, y Angel Pascual Martínez Soto. Los pioneros del cooperativismo agrario del crédito español (1880-1920). Valencia: CIRIEC-España $\mathrm{n}^{\mathrm{o}}$ 63, 2008, pp. 89-112.

Montero Gibert, José Ramón. La CEDA. El catolicismo social y político en la II república, 2 vols., Madrid: Ministerio de Trabajo, 1977.

Noguer, Narciso. Las cajas rurales en España y en el extranjero. Teoría, historia, guía práctica, legislación, estatutos, formularios. Madrid: Razón y Fe, 1912.

Orella, José Luis. Victor Pradera. Un católico en la vida pública de principios de siglo. Madrid: BAC, 2000.

ORELlA, José Luis. La formación del Estado nacional durante la Guerra Civil epañola. Madrid: Actas, 1990.

PAzos, Antón M. Teoría y acción en los pioneros del catolicismo social navarro (1891-1912). En XII Simposio Internacional de Teología. Pamplona: Ediciones Universidad de Navarra, 1991.

\footnotetext{
${ }^{32}$ J.L. ORELLA, La formación del Estado nacional, Madrid: Actas, 2001, pp. 149-158.
} 
Revuelta GonzÁlez, Manuel. Historia de la Compañia de Jesús en la España Contemporánea. Vol. II. Santander: Mensajero, 1991 .

Revuelta GonzÁlez, Manuel. La Iglesia y la educación: órdenes religiosas docentes; restablecimiento de la Compañía de Jesús en España y sus condicionamientos políticos. En Historia de la Educación en España y América, coord. Buenaventura Delgado Criado. Vol. 3. Madrid: Fundación Santa María, 1994, pp. 87-94.

Revuelta GonzÁlez, Manuel. El P. Sisinio Nevares. Etapas de su acción social y promoción de los sindicatos agrarios palentinos. Palencia. Publicaciones del Instituto Tello Téllez de Meneses, $\mathrm{n}^{\mathrm{o}} 76,2005$, pp. 355-393.

ROGER, Juan. Ideas politicas de los católicos franceses. Madrid: CSIC, 1951.

Rovan, Joseph. El catolicismo politico en Alemania. Madrid: Instituto de Estudios Políticos, 1964.

Winston, Colin M., y Carlos Laguna Pionno. La clase trabajadora y la derecha española (1900-1936). Madrid: Cátedra, 1989.

\section{EL COOPERATIVISMO AGRARIO - PRIMERA ACCIÓN DEL CATOLICISMO SOCIAL EN ESPAÑA}

\section{Res u m e n}

El catolicismo social agrario en España se desarrolló a iniciativa de sacerdotes y pioneros del catolicismo europeo, agrupando a pequeños agricultores y proporcionándoles una serie de servicios que impidió su proletarización. El éxito de su organización sirvió como posterior soporte a otras iniciativas asociativas como la prensa o la representatividad política. La importancia del catolicismo social en España impidió el éxito de un totalitarismo de signo fascista.

Palabras claves: sindicalismo; cooperativa; caja de ahorro; catolicismo social; León XIII.

\section{SPÓLDZIELCZOŚĆ ROLNICZA - PIERWSZA AKCJA KATOLICYZMU SPOŁECZNEGO W HISZPANII}

$$
\text { Streszczenie }
$$

Agrarny katolicyzm społeczny w Hiszpanii rozwinął się za sprawą kapłanów i pionierów europejskiego katolicyzmu, zrzeszając drobnych rolników i zapewniając szereg form pomocy, które pozwoliły uniknąć ich marginalizacji. Sukces tej organizacji posłużył później jako wsparcie dla innych inicjatyw partnerskich, takich jak prasa lub partie polityczne. Społeczny katolicyzm w Hiszpanii zaznaczył się mocno w zapobieżeniu sukcesowi ugrupowań spod znaku faszystowskiego totalitaryzmu.

Słowa kluczowe: syndykalizm; spółdzielnia; kasy oszczędnościowe; katolicyzm społeczny; Leon XIII.

\section{AGRICULTURAL COOPERATIVISM - FIRST ACTION OF SOCIAL CATHOLICISM IN SPAIN}

\section{S u m m a r y}

The agrarian social Catholicism in Spain was developed at the initiative of priests and pioneers of European Catholicism, grouping small farmers and providing a range of services which 
prevented their marginalization. The success of this organization later served as support other partnership initiatives such as the press or political representation. The social Catholicism in Spain prevented the success of fascist totalitarianism sign.

Key words: sindicalism; cooperative; credit institution; social Catholicism; Leon XIII. 